\title{
On the quantification of atmospheric carbonate carbon by thermal/optical analysis protocols
}

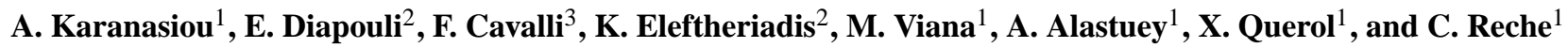 \\ ${ }^{1}$ Institute of Environmental Assessment and Water Research (IDAEA-CSIC), Barcelona, Spain \\ ${ }^{2}$ Institute of Nuclear Technology and Radiation Protection, Environmental Radioactivity Laboratory, National Centre of \\ Scientific Research "Demokritos", 15310 Ag. Paraskevi, Attiki, Greece \\ ${ }^{3}$ European Commission, Joint Research Centre, Institute of Environment and Sustainability, via E. Fermi, 2749, 21027 Ispra, \\ Italy
}

Received: 22 July 2010 - Published in Atmos. Meas. Tech. Discuss.: 25 November 2010

Revised: 13 October 2011 - Accepted: 30 October 2011 - Published: 10 November 2011

\begin{abstract}
The objective of this work was to study the possibility of identifying and quantifying atmospheric carbonate carbon (CC) by thermal-optical analysis. Three different temperature protocols, two modified NIOSH-like protocols (RT-QUARTZ-840 and RT-QUARTZ-700), and the EUSAAR_2 protocol were tested on filter samples containing known amounts of CC with the semi-continuous Sunset analyzer. Carbonate was quantified by the manual integration of the sharp peak appeared at the maximum temperature step of the inert mode. High recoveries of CC were achieved by all the thermal protocols. Using the EUSAAR_2 thermal protocol, more than $95 \%$ of CC evolved as OC during the maximum temperature step in inert atmosphere for CC amounts up to $56 \mu \mathrm{g}$. Using the RT-QUARTZ-840 protocol specifically developed for on-line analyses, CC completely evolves as OC during the maximum temperature step in the inert node, regardless of the $\mathrm{CC}$ concentration. However, the quantification of CC by the RT-QUARTZ-840 protocol suitable for the semi-continuous analyzer implies a high level of uncertainty (manual integration, residual contribution of organic carbon). Therefore, it is advisable to determine CC with an independent method (e.g. by acidic decomposition of $\mathrm{CO}_{3}^{2-}$ and subsequent detection of $\mathrm{CO}_{2}$ ) when other sample aliquots are available. The comparison of the peak integration method with the direct determination of the CC sample content by acidic $\mathrm{CO}_{2}$ release showed that the peak integration method provides always higher $\mathrm{CC}$ concentrations of about $33 \%$. Nevertheless, the determination of CC with the RT-QUARTZ-840 protocol may be considered in cases where on line monitoring instruments are used and for areas
\end{abstract}

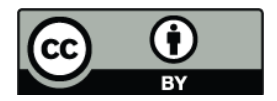

Correspondence to: A. Karanasiou (angeliki.karanasiou@idaea.csic.es) where CC concentrations are expected to be significant e.g. Southern European countries. This case study suggests that users of the semi continuous Sunset analyzer can manually integrate the sharp peak (if present) at the maximum temperature step of the He mode (between 128-130 and 160-165 s when using the RT-QUARTZ-840 protocol) and calculate the $\mathrm{CC}$ concentration though with a rather high error.

\section{Introduction}

Carbonaceous particulate matter, usually classified into two categories, organic carbon (OC) and elemental carbon (EC), constitutes an important component of the atmospheric aerosol forming typically 10 to $50 \%$ of the total particulate matter $\left(\mathrm{PM}_{10}\right)$ mass concentration (Putaud et al., 2004, 2010; Yttri et al., 2007; Pio et al., 2001). OC can be of both primary and secondary origin, i.e. emitted directly into the atmosphere or formed by the condensation of compounds produced in the atmosphere by photo-oxidation of volatile organic precursors (Fuzzi et al., 2006). In contrast, EC is exclusively of primary origin (incomplete combustion of carboncontaining fuels).

Thermal-optical analysis has been widely used for the determination of OC and EC (Phuah et al., 2009) in atmospheric aerosol samples. According to this method, the carbonaceous species are thermally desorbed firstly in an inert atmosphere $(\mathrm{He})$ and then in an oxidizing atmosphere (mixture of $\mathrm{He}$ and $\mathrm{O}_{2}$ ). Ideally, OC desorbs in the inert atmosphere while EC combusts in the oxidizing atmosphere at high temperature. However, some OC is pyrolytically converted to EC (char) when heated up in inert atmosphere. This process that darkens the filter, is used to correct for charring, by continuously monitoring the transmittance (or

Published by Copernicus Publications on behalf of the European Geosciences Union. 
reflectance) of the filter during the analysis (Bae et al., 2004; Birch and Cary, 1996). The most commonly employed thermal protocols for the analysis of OC and EC in atmospheric aerosols are the IMPROVE (Chow et al., 1993), the NIOSH (Birch and Cary, 1996), and the EUSAAR_2 (Cavalli et al., 2010) protocols. Although these protocols show good agreement for total carbon (TC) determination, they yield different OC and EC concentrations (Chow et al., 2001; Schmid et al., 2001). Furthermore, they are not all well characterized with respect to interferences by carbonate.

Carbonate carbon (CC), another primary carbonaceous species present in natural ground and building/demolition dust, is generally not considered in many atmospheric chemistry studies. The reason for this may be its low contribution to the atmospheric fine particle mass concentration in most studied areas (Sillanpää et al., 2005), along with the lack of a robust and popular technique to determine $\mathrm{CC}$ concentration in atmospheric aerosols (Jankowski et al., 2008).

However, CC concentrations may be significant in certain areas and/or under specific meteorological conditions. For instance, soil dust outbreaks may greatly increase the ambient PM air levels especially in Southern Europe and across the Mediterranean basin. Sillanpää et al. (2005) measured carbonaceous aerosol in six European cities (i.e. Duisburg, Prague, Amsterdam, Helsinki, Barcelona and Athens) and detected carbonate carbon (by thermal-optical analysis) in the aerosol coarse fraction $\left(\mathrm{PM}_{10}-\mathrm{PM}_{2.5}\right)$ of Athens and Barcelona. In that study, CC was mainly present as $\mathrm{CaCO}_{3}$ with an average coarse fraction concentration of $15.9 \mu \mathrm{g} \mathrm{m}^{-3}\left(9.8-29.2 \mu \mathrm{g} \mathrm{m}^{-3}\right)$ in Athens and $2.6 \mu \mathrm{g} \mathrm{m}^{-3}\left(0.3-6.3 \mu \mathrm{g} \mathrm{m}^{-3}\right)$ in Barcelona (over 7 weeks in spring-summer 2003), accounting, for $55 \%$ and $11 \%$ of the coarse aerosol mass concentration in Athens and Barcelona, respectively. In Athens, a daily average $\mathrm{PM}_{10}$ concentration of $441 \mu \mathrm{g} \mathrm{m}^{-3}$ was also reported during an intense dust event by the Greek Ministry of the Environment with an hourly $\mathrm{PM}_{10}$ mass concentration reaching at $2384 \mu \mathrm{g} \mathrm{m}^{-3}$ (Athanassiadou et al., 2006). In Eastern Mediterranean, severe dust events have been reported, where $\mathrm{PM}_{10}$ daily ( $24 \mathrm{~h}$ average) concentrations exceeded $200 \mathrm{\mu g} \mathrm{m}^{-3}$ in Crete (Gerasopoulos et al., 2006) and reached a maximum of $326 \mu \mathrm{g} \mathrm{m}^{-3}$ along Mediterranean Tunisian coasts over year 2002-2003 (Koçak et al., 2007). Recently, Querol et al. (2009) quantified the African dust contribution to $\mathrm{PM}_{10}$ concentration at 21 regional background sites across the Mediterranean basin. The highest mean annual net African dust contribution to $\mathrm{PM}_{10}$ was observed in the Eastern part of the Mediterranean Basin and specifically, at Finokalia (Crete, over year 2004-2006), and at Ayia Marina (Cyprus, over year 2003-2006) reaching values of $10 \mu \mathrm{g} \mathrm{m}^{-3}$ and $9 \mu \mathrm{g} \mathrm{m}^{-3}$, respectively. At these sites during African dust outbreaks, daily $\mathrm{PM}_{10}$ levels were frequently above $100 \mathrm{\mu g} \mathrm{m}^{-3}$ and the characterization of individual particles revealed that $\mathrm{CaCO}_{3}$ formed up 30-40\% of the $\mathrm{PM}_{10}$ particle number. Dust storms are also frequent in Eastern Asia. For example, at $\mathrm{Xi}^{\prime}$ an located at the margin of a dust source region (Loess Plateau, China), the average level of $\mathrm{CC}$ measured (by acidification) in $\mathrm{PM}_{2.5}$ during five dust storms in spring 2002 was $7.2 \mu \mathrm{g} \mathrm{m}^{-3}$ (Cao et al., 2005).

The decomposition temperature of carbonate may vary depending on a number of factors (Chow et al., 2001 and references therein), including the mixture of calcium carbonate with other materials, the chemical composition of the carbonate compound (e.g. $\mathrm{CaCO}_{3}$ vs. $\left.\mathrm{CaMg}\left(\mathrm{CO}_{3}\right)_{2}\right)$, and the crystal form of the carbonate compound (e.g. calcite vs. aragonite vs. amorphous $\mathrm{CaCO}_{3}$ ). Carbonate thermal decomposition is also expected to depend on the material grain size (Chow et al., 2001). Furthermore, as various protocols have different temperature set points and plateau duration, $\mathrm{CC}$ can be detected at different temperatures. Indeed, $\mathrm{CC}$ was reported to evolve during the maximum temperature step in $\mathrm{He}$, i.e. between $700{ }^{\circ} \mathrm{C}$ and $850^{\circ} \mathrm{C}$ (Miyazaki et al., 2007; Birch and Cary, 1996) for a NIOSH-type protocol (i.e. reaching $>700{ }^{\circ} \mathrm{C}$ in the inert atmosphere mode during the last temperature step only). In contrast, $\mathrm{CO}_{2}$ was observed to evolve from laboratory-grade calcium carbonate at the $550^{\circ} \mathrm{C}$ set point with the IMPROVE protocol (Chow et al., 2001). However, Cavalli et al. (2010) demonstrated recently that natural calcite decomposes at $650{ }^{\circ} \mathrm{C}$ but not at $550^{\circ} \mathrm{C}$ in the inert mode of the analysis performed with a Sunset OCEC laboratory analyzer. Actually, $\mathrm{CC}$ could well interfere with the determination of OC or EC, depending on carbonate characteristics, and on the thermal protocol employed (Sillanpää et al., 2005; Sciare et al., 2003; Schmid et al., 2001). If not accounted for, the interference of $\mathrm{CC}$ with the $\mathrm{OC}$ or EC signal can lead to an overestimation of the OC or EC concentration. This overestimation might be negligible for fine mode OC and EC concentrations, as the contribution of $\mathrm{CC}$ to $\mathrm{PM}_{2.5}$ is generally very low (Querol et al., 2004). But it can be significant for $\mathrm{PM}_{10}$ or coarse OC or EC concentration. Indeed, Koulouri et al. (2008) showed that without the subtraction of $\mathrm{CC}$, thermal-optical analysis of coarse aerosol samples from Finokalia in Crete (Greece) would overestimate organic carbon content by $20 \%$ when using a NIOSH-like protocol.

In previous works $\mathrm{CC}$ was determined by integrating the peak appeared during the transition to the maximum temperature step of the inert mode of a NIOSH-like protocol (Miyazaki et al., 2007; Xu et al., 2004; Schauer et al., 2003; Birch and Cary, 1996). Alternative methods were described by Jankowski et al. (2008) and Cavalli et al. (2010), which require a separate analysis for $\mathrm{CC}$ determination.

The objective of this study is to determine how well atmospheric carbonate can be identified and quantified using only the thermal optical analysis. Three different temperature protocols (namely EUSAAR_2 and two modified versions of the NIOSH protocol, RT-QUARTZ-840 and RT-QUARTZ700) were tested against standard samples containing known amounts of CC. The RT-QUARTZ-840 protocol was applied to ambient samples from sites characterised by frequent African dust intrusions: Barcelona (Spain) and Athens (Greece). Off-line thermal-optical measurements of CC in 
samples from Barcelona were confronted to other methods (fumigation, acidification). The precision of on-line CC measurements performed in Athens with the RT-QUARTZ-840 protocol was also investigated.

\section{Methodology}

\subsection{Instrumentation}

In this study two OCEC Sunset analyzers were used: a semicontinuous OCEC field instrument (Sunset Laboratory Inc.) installed at the N.C.S.R. "Demokritos" Athens urban background site (GAW-DEM, http://gaw.empa.ch/gawsis/reports. asp?StationID $=2076202728$ ) and a laboratory OCEC analyzer installed at Barcelona (IDAEA, http://www.idaea.csic. es/). This latter is primarily used for the analysis of $\mathrm{PM}_{10}$, $\mathrm{PM}_{2.5}$ and $\mathrm{PM}_{1}$ samples collected at a Barcelona urban site, belonging to the local air quality monitoring network and for samples collected at the EUSAAR regional background site, Montseny (MSY, http://www.eusaar.net/files/overview/ infrastructures-descript.cfm). For the determination of OC and EC on a routine basis the EUSAAR_2 thermal protocol is used.

The semi-continuous instrument is equipped with an inline parallel carbon denuder, so that the sample is denuded of volatile gases during sampling. A cyclone was used upstream of the instrument to pass particles smaller than $2.5 \mu \mathrm{m}$. Aerosol particles are collected at a sampling flow rate of $81 \mathrm{~min}^{-1}$ on a round 16-mm quartz fibre filter which is mounted inside the instrument. The quartz fibre filter is always installed with a second backup filter, mostly to serve as support for the front filter. After collection, the oven of the instrument is purged with helium and the temperature is increased in multiple programmed steps based on the selected thermal protocol. The evolved organic carbon flows through a manganese dioxide $\left(\mathrm{MnO}_{2}\right)$ oxidizing oven and all carbon is transformed into carbon dioxide $\left(\mathrm{CO}_{2}\right)$. The $\mathrm{CO}_{2}$ is then quantified by a non-dispersive infrared (NDIR) detector. The oven is cooled prior to the second part of the analysis, where the oven is purged with a mixture of $2 \%$ oxygen in helium and the sample is again heated in steps. During this stage, all remaining carbon on the filter, including elemental carbon, is oxidized, the oxidation products are carried through the $\mathrm{MnO}_{2}$ oven, and carbon is detected by the NDIR detector as $\mathrm{CO}_{2}$. For charring correction a He-Ne laser beam monitors the sample transmittance throughout the heating process. At the time where the laser signal returns to its initial value, the split point between OC and EC is set (Birch and Cary, 1996).

The operating principle of the laboratory OCEC analyzer is similar to the semi-continuous analyzer with the difference that the $\mathrm{CO}_{2}$ produced is converted into $\mathrm{CH}_{4}$ and detected by a Flame Ionization Detector (FID), which improves the limit of detection.

\subsection{Standard samples}

The studied CC concentration range covers extreme dust events reported in the literature, in particular by Koçak et al. (2007), by Gerasopoulos et al. (2006) and by Sillanpää et al. (2005). The chemical characterization of airborne African dust plumes suggests that it is mainly composed of silicate (i.e. of Al-felsic silicates and of Si-felsic silicates roughly in equal proportions) with $\mathrm{CaCO}_{3}$ representing at a very maximum $40 \%$ of the $\mathrm{PM}_{10}$ aerosol particle number (Querol et al., 2009; Kandler et al., 2007). This composition has been applied to estimate the maximum mass concentration of $\mathrm{CaCO}_{3}$ expected during the episodes mentioned above. The corresponding $\mathrm{CC}$ concentrations (in $\mu \mathrm{g} \mathrm{CC} \mathrm{cm}{ }^{-2}$ ) have been calculated for three cases differing for sampling conditions and analyzer configuration (Table 1). Case 1 represents a $24 \mathrm{~h}$ sampling with a flow rate of $1 \mathrm{~m}^{3} \mathrm{~h}^{-1}$ on a $47 \mathrm{~mm}$ diam filter; Case 2 corresponds to a $3 \mathrm{~h}$ sampling with a flow rate $0.48 \mathrm{~m}^{3} \mathrm{~h}^{-1}$ on a $16 \mathrm{~mm}$ diam filter and on-line analysis using the semi-continuous OCEC analyzer (i.e. conditions employed in Athens field study, Sect. 3.3); and finally Case 3 represents a $24 \mathrm{~h}$ sampling with a flow rate of $30 \mathrm{~m}^{3} \mathrm{~h}^{-1}$ on a $150 \mathrm{~mm}$ dia filter (i.e. conditions adopted by the field study in Barcelona, Sect. 3.3).

Thirty-two standard samples of CC were prepared in the laboratory by depositing known amounts of powdered calcium carbonate $\left(\right.$ Merck, $\left.\mathrm{CaCO}_{3}\right)$ on pre-weighted quartz fibre filter punches (PALLFLEX, Tissuquartz). Although commercial precipitated $\mathrm{CaCO}_{3}$ may differ from atmospheric carbonate, was previously used to prepare carbonate carbon standards (e.g. Jankowski et al., 2008; Chow et al., 2001). Weighing was conducted with a Sartorius microbalance after $48 \mathrm{~h}$ of equilibration in a room maintained at $20 \pm 1{ }^{\circ} \mathrm{C}$ and $50 \pm 5 \% \mathrm{RH}$ (according to EN12341, 1998). The filter punch ( $16 \mathrm{~mm}$ diam) loaded with $\mathrm{CaCO}_{3}$ was covered by a second blank filter punch to avoid any loss (in the semi-continuous instrument two filter punches are always used during the analysis). Standard samples containing 25$220 \mu \mathrm{g} \mathrm{CC} /$ punch were prepared. This is much larger than the $\mathrm{CC}$ amounts expected to be collected during dust events (Table 1), but an accurate reference value for lower concentrations could not be obtained by gravimetric analysis. In order to better simulate "airborne $\mathrm{CaCO}_{3}$ ", additional three test samples were prepared by collecting commercial precipitated $\mathrm{CaCO}_{3}$ suspended in a clean chamber on quartz fibre filters. A TOPAS 210 polydisperse aerosol atomizer was used for this purpose while the $\mathrm{CaCO}_{3}$ mass deposited on the quartz fibre filter was calculated by weighing on a 5 digit balance (Sartorius, BP211D). The CC concentration on the filter samples prepared with this method was in the range $10-56 \mu \mathrm{g}(\mathrm{C})$. All samples were subsequently analyzed off-line, using the semi-continuous OCEC field instrument (Sunset Laboratory Inc.). 
Table 1. Expected atmospheric CC concentrations during dust events based on previous published studies.

\begin{tabular}{lrrr}
\hline & $\begin{array}{c}\text { Gerasopoulos } \\
\text { et al. (2006) }\end{array}$ & $\begin{array}{c}\text { Koçak } \\
\text { et al. (2007) }\end{array}$ & $\begin{array}{c}\text { Sillanpää } \\
\text { et al. (2005) }\end{array}$ \\
\hline $\mathrm{PM}_{10}\left(\mu \mathrm{g} \mathrm{m}^{-3}\right)$ & 200 & 326 & \\
${\mathrm{Mineral} \mathrm{dust}\left(\mu \mathrm{g} \mathrm{m}^{-3}\right)}_{\mathrm{CaCO}_{3}\left(\mu \mathrm{g} \mathrm{m}^{-3}\right)}^{130}$ & 222 & \\
$\mathrm{CC} \mu \mathrm{g} \mathrm{cm}^{-2}(\mathrm{CASE} 1)$ & 26 & 44 & 29 \\
$\mathrm{CC} \mu \mathrm{g} \mathrm{cm}^{-2}$ (CASE 2) & 5 & 9 & 3 \\
$\mathrm{CC} \mu \mathrm{g} \mathrm{cm}^{-2}$ (CASE 3) & 2 & 4 & 3 \\
& 13 & 22 & 15 \\
\hline
\end{tabular}

\subsection{Thermal protocols}

In this work, three different thermal protocols were applied: (1) RT-QUARTZ-840, a NIOSH-like protocol with a maximum temperature of $840^{\circ} \mathrm{C}$ in the He-mode which is the default thermal protocol in the Sunset semi-continuous analyzer, (2) RT-QUARTZ-700, a modified NIOSH protocol with a maximum temperature of $700^{\circ} \mathrm{C}$ in the He-mode and (3) EUSAAR_2 protocol with a maximum temperature of $650^{\circ} \mathrm{C}$ in the He-mode. A detailed description of each protocol is given in Table 2 .

Briefly, a NIOSH-like protocol (NIOSH, 1999) with a maximum temperature in the He-mode around $840^{\circ} \mathrm{C}$ has been extensively used for urban aerosol samples. When applying this protocol, Subramanian et al. (2006) have observed loss of light-absorbing carbon in the He-mode. Thus, they suggested lowering the maximum temperature to $700^{\circ} \mathrm{C}$, in order to limit premature evolution of EC. Chow et al. (2001) also suggested that the fraction of carbon evolving at around $850^{\circ} \mathrm{C}$ in inert-mode may be EC, which is oxidized by oxygen supplied by mineral oxides in the particle mixture on the filter. Nevertheless, the increase in light transmittance and reflectance observed at $850^{\circ} \mathrm{C}$ in the He stage could be also attributed to the evolution of light-absorbing OC products or of pyrolytic carbon (Yu et al., 2002). Birch and Cary (1996) found that in a NIOSH-like protocol CC evolves during the maximum temperature step of the inert mode of the analysis between $700-850^{\circ} \mathrm{C}$. Thus, in a NIOSH-like protocol, this carbon peak, when present in ambient aerosol samples, could be attributed to CC so its concentration is determined by the manual integration of this peak.

EUSAAR_2 has been recently developed for regional background sites in order to improve the accuracy of the discrimination between OC and EC. The use of lower temperature steps and of longer residence times aims at the reduction of pyrolysis and at a more complete evolution of OC (by favouring its volatilization), while early evolution of light absorbing carbon species is prevented by lowering the maximum temperature in the He-mode. The analysis of natu- ral calcite sample with this protocol showed that $\mathrm{CC}$ decomposes in the inert mode around $650^{\circ} \mathrm{C}$ (Cavalli et al., 2010).

\subsection{Fumigation with $\mathrm{HCl}$}

For comparison with the determination of $\mathrm{CC}$ by the RTQUARTZ-840 protocol, two high-loaded urban aerosol samples from Barcelona, as well as a standard carbonate sample, were fumigated with $\mathrm{HCl}$ prior to thermal-optical analysis, for the removal of their CC content (Cachier et al., 1989). During the fumigation procedure, the filter punches were placed on a perforated tray and set above a glass beaker containing concentrated hydrochloric acid (Merck, $37 \%$ ). They were exposed to the acid vapors for about one hour and then were placed in a clean hood for one hour again, in order to allow the residual acid to volatilize. It must be noted however that this procedure has been known to cause damage in the combustion oven of the OCEC analyzer due to the possible incomplete volatilization of the residual acid (Cavalli et al., 2010).

\subsection{Direct determination of $\mathrm{CC}$ by acidification and subsequent $\mathrm{CO}_{2}$ detection}

Specific techniques for determining carbonate concentrations in various matrices have been known for more than $15 \mathrm{yr}$ (Pio et al., 1994 and references therein). The determination of CC in atmospheric PM samples deposited on filters by acidification and determination of the $\mathrm{CO}_{2}$ evolved as first described by Cadle et al. (1980) and validated by Pio et al. (1994) is simple, accurate, and easily implementable by laboratories that already perform OC and EC analyses. Indeed, suitable glassware that contains the concentrated phosphoric acid $\left(\mathrm{H}_{3} \mathrm{PO}_{4}\right)$ is the only equipment needed if use is made of the $\mathrm{CO}_{2}$ detection chain of the OCEC instrument. The glass enclosure has to be fully flushed by a carrier gas (He). The filter punch is dropped into the concentrated phosphoric acid $\left(\mathrm{H}_{3} \mathrm{PO}_{4}\right)$, and $\mathrm{CO}_{2}$ that evolves (Eq. 1), is carried to the detector of a commercial OCEC analyzer by the carrier gas.

$\mathrm{O}_{3}^{2-}+2 \mathrm{H}^{+} \rightarrow \mathrm{CO}_{2}+\mathrm{H}_{2} \mathrm{O}$

Spiking quartz fibre filter punches with known amounts of $\mathrm{CC}$ contained in $10 \mu \mathrm{l}$ of $\mathrm{Na}_{2} \mathrm{CO}_{3}$ solutions, we checked that the $\mathrm{CC}$ recovery of this technique is $99 \%$ over the range $1.8-$ $12 \mu \mathrm{g} \mathrm{CC}$.

\section{Results}

\subsection{Detection and recovery of carbonate}

We firstly tested the recovery of $\mathrm{CC}$ by the three different protocols, namely RT-QUARTZ-840, RT-QUARTZ700 (version for semi-continuous analyzer) and EUSAAR_2. Standard samples containing $25-220 \mu \mathrm{gCC} /$ sample were 
Table 2. Thermal protocols used: Temperature $\left({ }^{\circ} \mathrm{C}\right)$, Duration (s).

\begin{tabular}{llrrr}
\hline & & RT-QUARTZ-840 & RT-QUARTZ-700 & EUSAAR_2 \\
\hline Step & Carbon peak & $\begin{array}{r}\text { Temperature, } \\
\text { Duration }\end{array}$ & $\begin{array}{r}\text { Temperature, } \\
\text { Duration }\end{array}$ & $\begin{array}{r}\text { Temperature, } \\
\text { Duration }\end{array}$ \\
\hline $\mathrm{He} 1$ & OC1 & 600,95 & 600,95 & 200,120 \\
$\mathrm{He} 2$ & OC2 & 840,90 & 700,90 & 300,150 \\
$\mathrm{He} 3$ & OC3 & 0,33 & 0,33 & 450,180 \\
$\mathrm{He} 4$ & OC4 & 550,2 & 550,2 & 650,180 \\
$\mathrm{He} 5$ & & & & 0,33 \\
$\mathrm{He} / \mathrm{O}_{2} 1$ & EC1 & 550,30 & 550,30 & 500,120 \\
$\mathrm{He} / \mathrm{O}_{2} 2$ & EC2 & 550,25 & 550,25 & 550,120 \\
$\mathrm{He} / \mathrm{O}_{2} 3$ & EC3 & 650,45 & 650,45 & 700,70 \\
$\mathrm{He} / \mathrm{O}_{2} 4$ & EC4 & 870,80 & 870,80 & 850,80 \\
\hline
\end{tabular}

analysed. The three thermal protocols tested, provided a rather accurate estimate of the CC content (Figs. 1, 2 and 3). The regression slope was about 0.90 , with an $R^{2}$ value close to 1 . The intercepts of the regressions in Figs. 1, 2, 3 were negligible equal to $-0.003,-0.002$ and +0.004 and respectively. This recovery test demonstrates that $\mathrm{CC}$ decomposes almost completely during thermal optical analysis regardless of the protocol implemented. Since a recovery of $90 \%$ was found for these high CC content levels, it can be assumed that at least similar recovery rates can be obtained with lower CC amounts corresponding to atmospheric dust concentrations.

In order to better characterise the behaviour of $\mathrm{CC}$ in relation to each temperature protocol, we conducted further experiments using the test samples which were prepared from precipitated $\mathrm{CaCO}_{3}$ suspended in a clean chamber and sampled on a quartz fibre filter as aerosol particles. The CC content of the filter samples prepared with this method was in the range $10-56 \mu \mathrm{g}(\mathrm{CC})$. These filter samples were analysed using the RT-QUARTZ-840 and the EUSAAR_2 protocols, which are the most widely used at European monitoring sites with both the semi-continuous and the laboratory OCEC analyzers.

The thermograms obtained with the EUSAAR_2 protocol from the analysis of 10,15 and $56 \mu \mathrm{g}$ of CC indicated that $100,96 \%$ and $95 \%$ of CC respectively evolved in the OC4 step of the analysis at $650^{\circ} \mathrm{C}$, and the remaining in the EC3 step at $700^{\circ} \mathrm{C}$. In Figs. 4 and 5 the thermograms of the analysis of 10 and $56 \mu \mathrm{g} \mathrm{CC}$ by EUSAAR_2 protocol are given. The thermograms obtained with the RT-QUARTZ-840 protocol showed one single sharp peak at the maximum temperature step $\left(840^{\circ} \mathrm{C}\right)$ of the He mode regardless of the deposited amount of $\mathrm{CC}$ up to $56 \mu \mathrm{g}$ (Fig. 6).

In general, for the amount of CC collected even during extreme dust events as reported in Table 1, CC will completely evolve in the inert mode of the analysis with all three thermal protocols (at $T \leq 650,700$, and $840^{\circ} \mathrm{C}$ for EUSAAR_2, RT-QUARTZ-700 and RT-QUARTZ-840, respectively), and

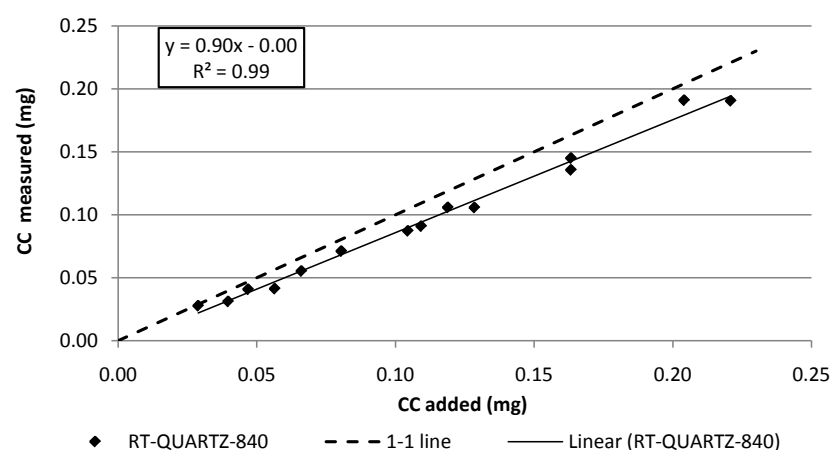

Fig. 1. Regression between CC quantities measured by the RTQUARTZ-840 thermal protocol and CC quantities initially added on filter blanks.

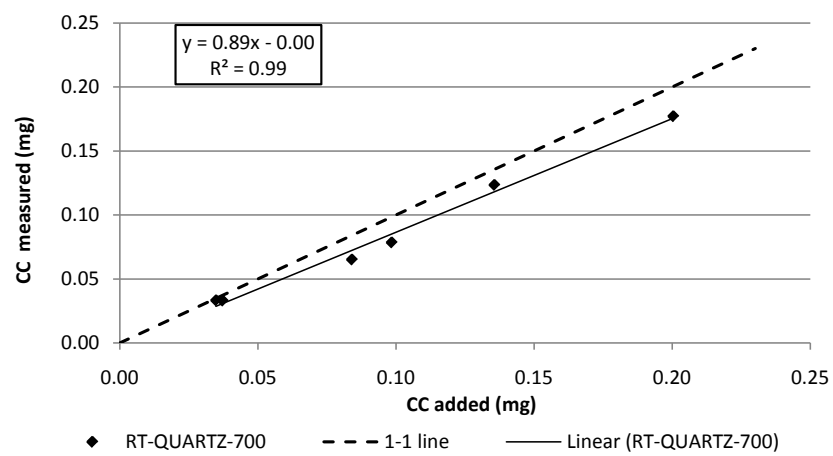

Fig. 2. Regression between $\mathrm{CC}$ quantities measured by the RTQUARTZ-700 thermal protocol and CC quantities initially added on filter blanks.

will therefore interfere only with the determination of OC. The concentration of $\mathrm{CC}$ might be determined by integrating the $\mathrm{CO}_{2}$ peak that could be specifically attributed to the decomposition of $\mathrm{CC}$. 


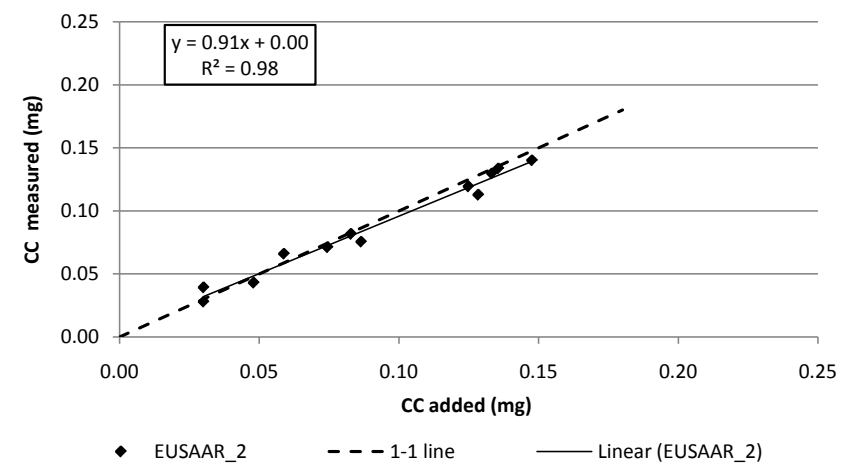

Fig. 3. Regression between $\mathrm{CC}$ quantities measured by the EUSAAR_2 thermal protocol and CC quantities initially added on filter blanks.

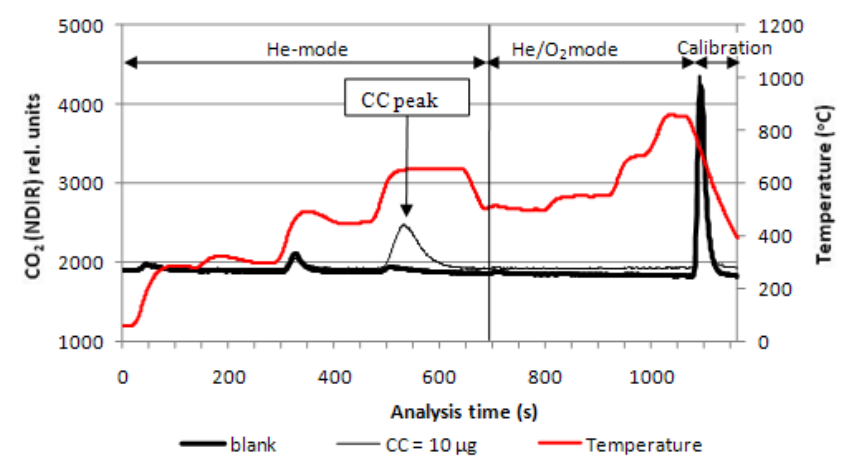

Fig. 4. EUSAAR_2 thermogram for a blank and a CC-loaded filter $(10 \mu \mathrm{g})$ (He-mode: 1-230 s, He/O 2 -mode: $231-410 \mathrm{~s}$ and Calibration-mode: $410-510 \mathrm{~s}$ ). The vertical line represents the splint point between OC and EC. The response of the NDIR detector is given in relative units.

\subsection{CC peak integration and comparison with fumigation by $\mathrm{HCl}$}

In this study we applied the RT-QUARTZ-840 protocol to determine $\mathrm{CC}$ in real atmospheric samples by manually integrating the sharp "OC2" peak occurring during the transition to the maximum temperature plateau in the inert mode of the analysis. It should be noted that CC is not automatically determined by the OCEC Sunset analyzers: the analyst has to calculate the $\mathrm{CC}$ amount (if detected) by using the manual integration option available in the calculation program. Based on the feature of the CC peak observed on CC standard thermograms, $\mathrm{CC}$ was estimated by integrating the $\mathrm{OC} 2$ peak of the RT-QUARTZ-840 protocol between 128-130 and 160$165 \mathrm{~s}$. The uncertainty of the manual integration due to the definition of the time integral of the $\mathrm{CC}$ peak was calculated. The definition of the time integral influences the $\mathrm{CC}$ concentration by $3-12 \%$ with the highest uncertainty associated to the lowest concentrations.

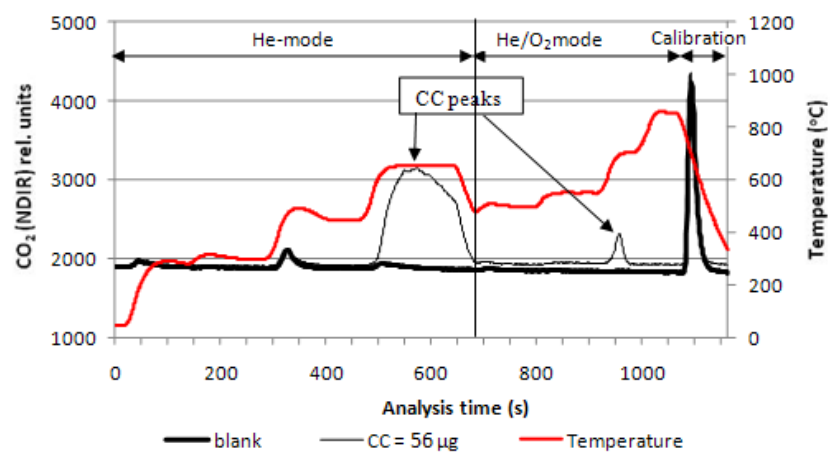

Fig. 5. EUSAAR_2 thermogram for a blank and a CC-loaded filter $(56 \mu \mathrm{g})$ (He-mode: 1-230 s, He/O ${ }_{2}$-mode: $231-410 \mathrm{~s}$ and Calibration-mode: $410-510 \mathrm{~s}$ ). The vertical lines represents the splint point between OC and EC. The response of the NDIR detector is given in relative units.

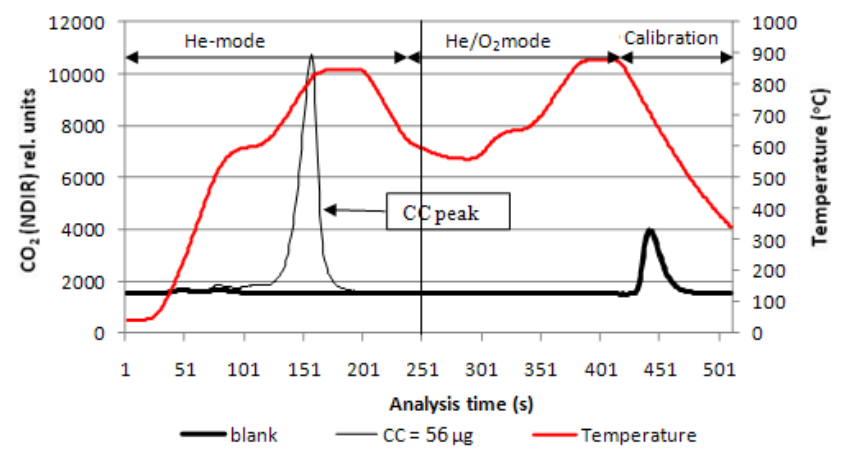

Fig. 6. RT -QUARTZ- 840 thermogram for a blank and a CC-loaded filter $(56 \mu \mathrm{g})$ (He-mode: 1-673 s, He/O 2 -mode: 674-1063 s and Calibration-mode: 1064-1163 s). The vertical line represents the splint point between OC and EC. The response of the NDIR detector is given in relative units.

This methodology was tested versus the $\mathrm{HCl}$ fumigation procedure for the removal of CC (NIOSH, 1999). One standard CC filter sample, as well as two urban aerosol filters collected in Barcelona site (with high CC content), were fumigated with $\mathrm{HCl}$, prior to being analyzed by the RT-QUARTZ840 protocol. The fumigation treatment almost entirely removed CC (by approximately $99 \%$ according to the initial quantity added) from the standard CC sample. The thermograms obtained from one of the urban aerosol samples, prior and after $\mathrm{HCl}$ fumigation, are presented in Fig. 7. Fumigation led to a large decrease of the peak attributed to carbonate carbon (by approximately $86 \%$, in both of the ambient filter samples). However, we noticed changes in the organic carbon volatility properties after the fumigation. The area of $\mathrm{OC} 1$ peak was larger after the fumigation. This indicates that a fraction of OC, which was evolving as $\mathrm{OC} 2\left(840^{\circ} \mathrm{C}\right)$ from the untreated sample, evolves at lower temperature (i.e. $600^{\circ} \mathrm{C}$ ) after the treatment with $\mathrm{HCl}$. Moreover, fumigation with $\mathrm{HCl}$ has been shown to cause loss of volatile organic 


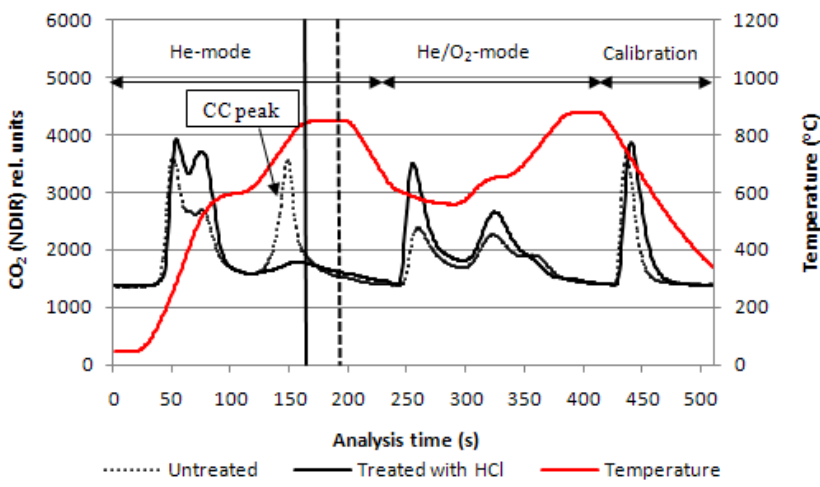

Fig. 7. RT-QUARTZ-840 thermogram for an ambient aerosol sample filter treated with $\mathrm{HCl}$ and untreated (He-mode: $1-230 \mathrm{~s}, \mathrm{He} / \mathrm{O}_{2}$ mode: $231-410 \mathrm{~s}$ and Calibration-mode: $410-510 \mathrm{~s}$ ). The vertical lines represent the splint point between $\mathrm{OC}$ and $\mathrm{EC}$. The response of the NDIR detector is given in relative units.

compounds. Salts of volatile organic acids, if present, will react with $\mathrm{HCl}$ and will be correspondingly missing from the OC fraction if fumigation is used (Chow et al., 1993). Consequently the decrease of OC2 peak area cannot be solely attributed to CC loss. Furthermore, a small wide peak (about $14 \%$ of the OC2 peak area) remains after the treatment with $\mathrm{HCl}$, suggesting the presence of organic compounds that coevolve with $\mathrm{CC}$ in the $\mathrm{OC} 2$ peak during the highest temperature step in the He mode. The estimation of CC should therefore be based on the loss of TC in the sample aliquot after fumigation. However, the CC concentration in the sample prior to the fumigation (as determined by the integration of the OC2 peak in the untreated sample) corresponds to the TC loss after fumigation in one of the two ambient samples only: in the second sample, the TC loss after the fumigation was twice as high as the $\mathrm{CC}$ concentration determined by the integration of the OC2 peak in the untreated sample. This suggests that fumigation is able not only to eliminate $\mathrm{CC}$, but also to cause losses of organic compounds like organic acids. In conclusion, it was not possible to validate the determination of $\mathrm{CC}$ in ambient samples by integration of the $\mathrm{OC} 2$ peak through a comparison with the fumigation method.

\subsection{Urban aerosol measurements}

$\mathrm{CC}$ was determined by integrating the sharp peak at the maximum temperature step of the He mode of the RTQUARTZ-840 protocol (see Sect. 3.2) for two sets of ambient samples representative of Mediterranean urban/urban background aerosols collected in Barcelona and Athens during different periods. At the urban monitoring site in Barcelona (IDAEA-CSIC), CC was determined off-line in $\mathrm{PM}_{10}, \mathrm{PM}_{2.5}$ and $\mathrm{PM}_{1}$ in $24 \mathrm{~h}$ - integrated samples collected during February-August 2008 using a MCV high volume sampler set at $30 \mathrm{~m}^{3} \mathrm{~h}^{-1}$ (MCV S.A, www.mcvsa.com). At the urban background site in Athens (GAW-DEM), CC was determined on-line from $3 \mathrm{hr}$ - integrated samples by the semi-continuous Sunset instrument during November 2009February 2010. A PM 2.5 cut-off cyclone was employed along with the semi-continuous OCEC analyzer.

$\mathrm{OC}, \mathrm{EC}$ and $\mathrm{CC}$ concentrations recorded at the sampling sites in Athens and Barcelona are presented in Table 3. $\mathrm{CC}$ was not detected in $\mathrm{PM}_{1}$ ambient samples collected in Barcelona. The lowest $\mathrm{CC}$ concentration that could be detected in $\mathrm{PM}_{10}$ and $\mathrm{PM}_{2.5}$ was $0.04 \mu \mathrm{g} \mathrm{m}^{-3}$. As expected, $\mathrm{CC}$ concentrations in $\mathrm{PM}_{10}$ and $\mathrm{PM}_{2.5}$ were generally low with respect to $\mathrm{OC}$ but $\mathrm{CC}$ concentration in $\mathrm{PM}_{10}$ reached half of the EC ambient concentration at Barcelona on 19 June 2008. This fact points out the importance to ensure that $\mathrm{CC}$ evolves together with OC rather than with EC during the thermaloptical analysis. On average, the concentration of CC in $\mathrm{PM}_{10}$ was $0.59 \mu \mathrm{g} \mathrm{m}^{-3}$ at the Barcelona site, accounting for about $10 \%$ of the total carbon concentration.

For the maximum concentrations of $\mathrm{CC}$ observed at both Athens and Barcelona sites, back-trajectories analysis (Draxler and Rolph, 2010) revealed African dust intrusions (Fig. 8). For the Athens site, these events were detected on 18-19 November 2009 and 18-20 February 2010 while for Barcelona occurred on 25-26 June 2008.

For the $24 \mathrm{~h}$ samples collected in Barcelona, a complete chemical characterisation was available. The measured CC concentrations were compared to the maximum $\mathrm{CC}$ concentrations calculated as $0.3(12 / 40)$ times the corresponding total calcium concentration determined by Inductively coupled plasma atomic emission spectroscopy, ICP-AES (as if all $\mathrm{Ca}^{2+}$ were in the form of $\mathrm{CaCO}_{3}$ ). The results of $\mathrm{Ca}^{2+}$, maximum expected $\mathrm{CC}$ and measured $\mathrm{CC}$ concentrations are presented in Table 4. Almost for all samples (except for the samples on 27 August 2008 and 21 July 2008) the measured $\mathrm{CC}$ concentration was lower than the upper limit indicating that $\mathrm{CC}$ was not overestimated by integrating the $\mathrm{OC} 2$ peak of the RT-QUARTZ-840 protocol. Generally, $\mathrm{Ca}$ and CC correlated well $\left(R^{2}=0.85\right)$, and measured CC concentration was $55 \pm 11 \%$ (99\% confidence level) of the maximum CC calculated from $\mathrm{Ca}^{2+}$ measurements.

Furthermore, for a set of samples, i.e. 14, from Barcelona urban site and EUSAAR regional background site, Montseny, Spain (MSY, http://www.eusaar.net/files/ overview/infrastructures-descript.cfm) the CC concentrations measured by peak integration were compared to those directly measured by acidification and subsequent $\mathrm{CO}_{2}$ detection. CC determined by the two different methods correlated well $\left(R^{2}=0.98\right)$ and the CC concentration determined by peak integration was $1.33( \pm 0.06)$ times plus $0.19( \pm 0.12)$ $\mu \mathrm{g} \mathrm{m}^{-3}$ the concentration determined by acidification, Fig. 9 . For the studied sites the slope of the relationship indicates systematic differences between the two methods. It seems that the peak integration method gives constantly higher CC concentrations than the acidification method, probably due to the contribution of some OC fraction. The presence of an intercept indicates that the peak integration can provide 

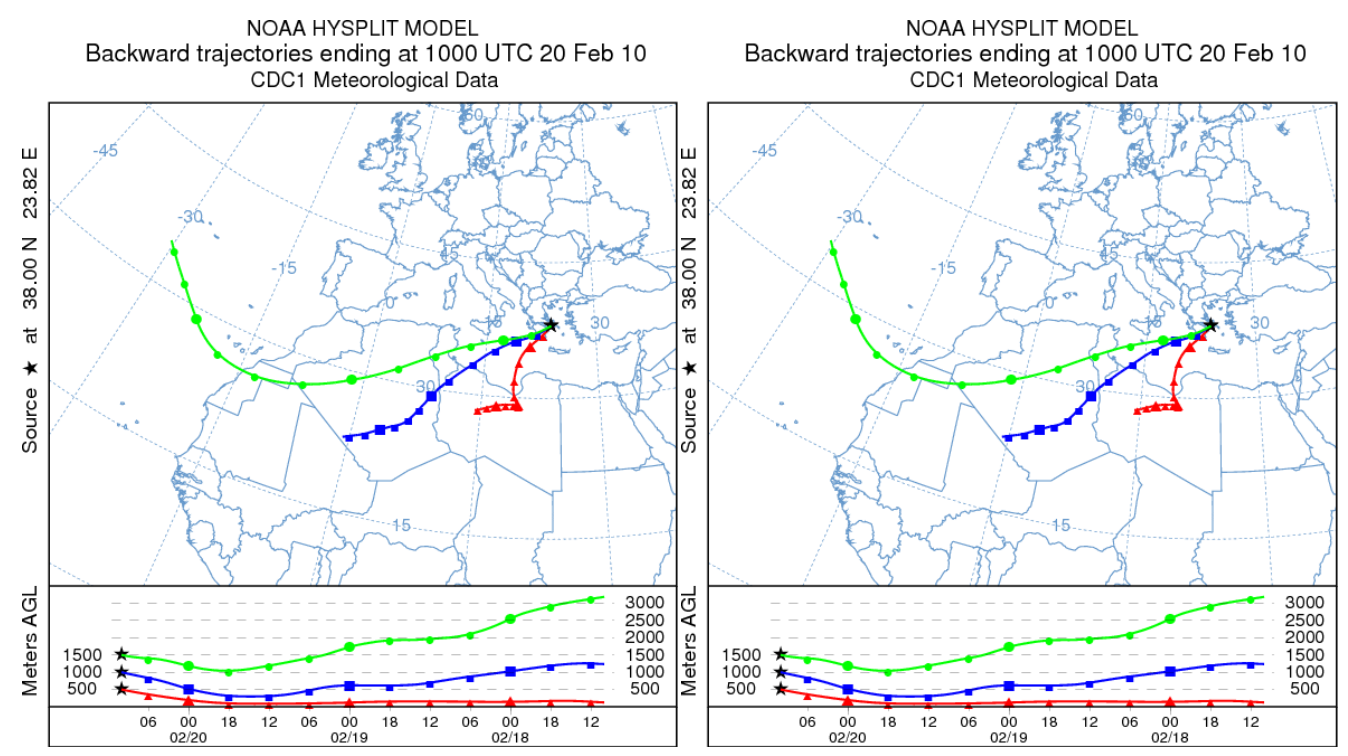

Fig. 8. HYSPLIT back-trajectory analysis at different vertical levels (red: $500 \mathrm{~m}$, blue: $1000 \mathrm{~m}$, green: $1500 \mathrm{~m}$ ) ending over Barcelona (26 June 2008) and Athens (20 February 2010) showing dust episodes.

Table 3. OC, EC and $\mathrm{CC}$ mean daily concentrations $\left[\mu \mathrm{g} \mathrm{m}^{-3}\right]$, measured at Barcelona site during February-August 2008 and at Athens site during October 2009-February 2010 (semi-continuous measurements $3 \mathrm{~h}$ ).

\begin{tabular}{lclllll}
\hline$\mu \mathrm{g} \mathrm{m}^{-3}$ & $\begin{array}{c}\mathrm{PM}_{10} \text { Barcelona, } \\
(6 / 2008-11 / 2008) \\
N=10 \text { days }\end{array}$ & $\begin{array}{c}\mathrm{PM}_{2.5} \text { Barcelona, } \\
(6 / 2008-11 / 2008) \\
N=8 \text { days }\end{array}$ & $\begin{array}{c}\mathrm{PM}_{2.5} \text { Athens, } \\
(11 / 2009-2 / 2010) \\
N=72 \text { days }\end{array}$ \\
\hline & Mean & Min.-Max. & Mean & Min.-Max. & Mean & Min.-Max. \\
\hline EC & 1.74 & $1.01-3.10$ & 1.08 & $0.27-2.64$ & 0.61 & $0.22-1.61$ \\
OC & 4.01 & $3.00-4.92$ & 3.12 & $1.42-4.88$ & 2.10 & $0.86-6.40$ \\
CC & 0.59 & $0.04-1.27$ & 0.22 & $0.04-0.51$ & 0.07 & $0.00-0.40$ \\
\hline
\end{tabular}

${ }^{*}$ CC determined by integrating the OC2 peak of the RT-QUARTZ-840 protocol

a non-zero CC concentration also for samples not containing any CC. During the temperature step that carbonate decomposes other organic compounds (like organic acids) might also decompose resulting in an artificial CC concentration. CC concentrations determined by acidification resulted $46 \pm 2 \%\left(R^{2}=0.98\right)$ of the maximum CC concentrations calculated from $\mathrm{Ca}^{2+}$ concentrations. In the studied areas, roughly half of the calcium appears to be associated to carbonate. The remaining calcium can be present in other forms such as $\mathrm{CaO}, \mathrm{CaSO}_{4}$ and $\mathrm{Ca}^{2+}$ from sea salt (i.e. the portion which is not balanced by $\mathrm{CO}_{3}, 75 \%$ in mass) (Kandler et al., 2007; Hoornaert et al., 1996).

The analysis of aerosol samples from Barcelona urban site, EUSAAR regional background site (MSY) and Athens urban background site evidences that in Southern European countries CC may constitute a significant fraction of the atmospheric carbonaceous matter, and therefore contribute to the

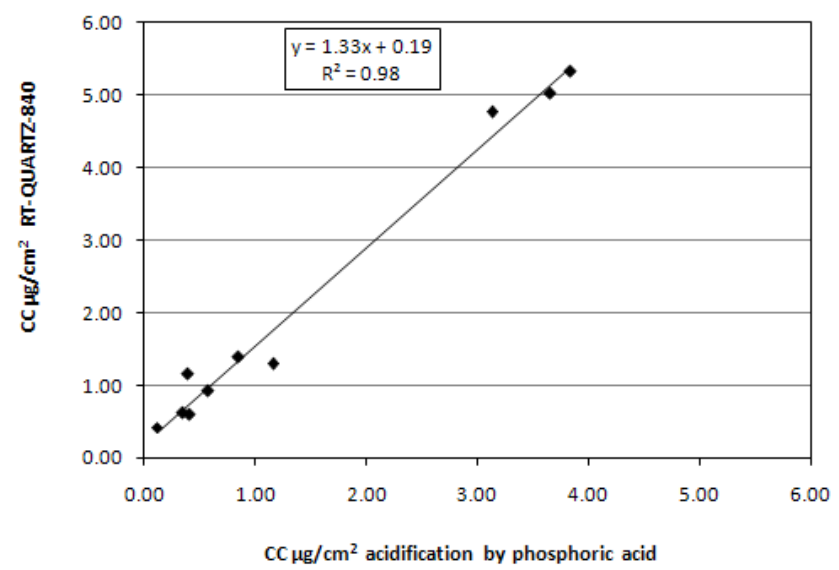

Fig. 9. Regression between $\mathrm{CC}$ concentrations determined by the RT-QUARTZ-840 thermal protocol using the manual integration and by direct determination by acidification with phosphoric acid.

exceedances of daily and annual $\mathrm{PM}_{10}$ limit values (Escudero et al., 2007). In these cases, it is essential that CC is quantified along with the other carbonaceous constituents since, if not considered, it would interfere with the OC (or even EC) signal, leading to artifacts in OC, EC determination. Especially under certain meteorological conditions, it can be demonstrated that high CC result from long range transport of natural Saharan desert dust. 
Table 4. Comparison of the maximum CC concentrations (determined as 0.3 times the calcium concentration) with the measured $\mathrm{CC}$ concentrations for $\mathrm{PM}_{10}$ and $\mathrm{PM}_{2.5}$ samples

\begin{tabular}{llll}
\hline Date & Ca measured by ICP-AES & maximum CC & measured CC \\
\hline $\mathrm{PM}_{10}$ & $\mu \mathrm{g} \mathrm{m}^{-3}$ & $\mu \mathrm{g} \mathrm{m}^{-3}$ & $\mu \mathrm{g} \mathrm{m}^{-3}$ \\
\hline $18 / 06 / 2008$ & 6.19 & 1.86 & 1.20 \\
$19 / 06 / 2008$ & 7.33 & 2.20 & 1.27 \\
$26 / 06 / 2008$ & 7.42 & 2.23 & 1.09 \\
$01 / 07 / 2008$ & 6.29 & 1.89 & 1.14 \\
$15 / 07 / 2008$ & 1.72 & 0.52 & 0.42 \\
$29 / 07 / 2008$ & 1.37 & 0.41 & 0.40 \\
$26 / 08 / 2008$ & 1.22 & 0.37 & 0.32 \\
$27 / 08 / 2008$ & 1.25 & 0.37 & 0.41 \\
$22 / 10 / 2008$ & 0.13 & 0.04 & 0.04 \\
$23 / 10 / 2008$ & 0.20 & 0.06 & 0.05 \\
\hline $\mathrm{PM}_{2.5}$ & $\mu \mathrm{g} \mathrm{m}{ }^{-3}$ & $\mu \mathrm{g} \mathrm{m}^{-3}$ & $\mu \mathrm{g} \mathrm{m}{ }^{-3}$ \\
\hline $18 / 06 / 2008$ & 2.30 & 0.69 & 0.33 \\
$26 / 06 / 2008$ & 4.44 & 1.33 & 0.62 \\
$01 / 07 / 2008$ & 3.27 & 0.98 & 0.05 \\
$15 / 07 / 2008$ & 0.38 & 0.12 & 0.10 \\
$21 / 07 / 2008$ & 0.44 & 0.13 & 0.22 \\
$12 / 08 / 2008$ & 2.06 & 0.62 & 0.37 \\
$23 / 10 / 2008$ & 0.13 & 0.04 & 0.04 \\
$04 / 11 / 2008$ & 0.08 & 0.02 & $\mathrm{~N} . \mathrm{D}$ \\
\hline
\end{tabular}

\section{Conclusions}

The objective of this work was to study the possibility of identifying and quantifying atmospheric carbonate by thermal-optical analysis. Three different temperature protocols, two modified NIOSH-like protocols (RT-QUARTZ-840 and RT-QUARTZ-700), and the EUSAAR_2 protocol were tested on filter samples containing known amounts of CC. High recoveries of $\mathrm{CC}$ were achieved by all the thermal protocols tested for CC amounts up to $220 \mu \mathrm{g}$ (CC). Using the EUSAAR_2 thermal protocol, more than $95 \%$ of CC evolved as OC during the maximum temperature step in inert atmosphere for $\mathrm{CC}$ amounts up to $56 \mu \mathrm{g}(\mathrm{C})$, corresponding to the mass of $\mathrm{CC}$ that would be collected during extreme desert dust events (i.e. with $\mathrm{PM}_{10}$ concentration above $200 \mu \mathrm{g} \mathrm{m} \mathrm{m}^{-3}$ ). Using the RT-QUARTZ-840 protocol specifically developed for on-line analyses, CC completely evolves as OC, regardless of the $\mathrm{CC}$ amount.

The quantification of CC with RT-QUARTZ-840 protocol (a NIOSH- like protocol) suitable for the semi-continuous analyzer implies a high level of uncertainty (manual integration, residual contribution of organic carbon). Therefore, it is advisable to determine $\mathrm{CC}$ with an independent method (e.g. by acidic decomposition of $\mathrm{CO}_{3}^{2-}$ and subsequent detection of $\mathrm{CO}_{2}$ ) when other sample aliquots are available. The comparison of the peak integration method with the direct determination of the $\mathrm{CC}$ sample content by acidic $\mathrm{CO}_{2}$ release showed that the peak integration method provides always higher $\mathrm{CC}$ concentrations than the acidification method (slope of the regression equal to 1.33). Nevertheless, the de- termination of CC with the RT-QUARTZ-840 protocol may be considered in cases where on line monitoring instruments are used and for areas where $\mathrm{CC}$ concentrations are expected to be significant e.g. Southern European countries. The results of this case study suggest that users of the semi continuous analyzers could manually integrate the sharp OC2 peak (if present) at the maximum temperature step of the $\mathrm{He}$ mode (between 128-130 and 160-165 s when using the RTQUARTZ-840 protocol) and thus calculate the CC concentration though with a rather high error.

The RT-QUARTZ-840 protocol was used to determine CC in real atmospheric samples. Over a set of samples, CC represented $2.5 \%$ of TC in $\mathrm{PM}_{2.5}$ in Athens, and 5.0 and $9.3 \%$ of $\mathrm{PM}_{2.5}$ and $\mathrm{PM}_{10}$, respectively, in Barcelona. The amount of CC measured in the filters collected in Barcelona correlated quite well with the amounts of $\mathrm{Ca}^{2+}$ as determined by ICP-AES, and suggest that about half of the calcium atoms were associated with carbonate at Barcelona urban site.

Acknowledgements. We would like to thank the reviewers for the constructive comments and suggestions on improving the manuscript. This work was partly carried out in the framework of the EU FP6 Infrastructure Project EUSAAR, Contract No. RII3-CT-2006-026140, (www.eusaar.net). The authors gratefully acknowledge the NOAA Air Resources Laboratory (ARL) for the provision of the HYSPLIT transport and dispersion model and READY website (http://www.arl.noaa.gov/ready.php) used in this publication. The authors also thank the Spanish Ministry of Science and Innovation (Ramón y Cajal Programme).

Edited by: B. Buchmann

\section{References}

Athanassiadou, M., Flocas, H., Harrison, M. R. J., Hort, M. C., Witham, C. S., and Millington, S.: The dust event of 17 April 2005 over Athens, Greece, Weather, 61, 125-131, 2006.

Bae, M. S., Schauer, J. J., DeMinter, J. T., Turner, J. R., Smith, D., and Cary, R. A.: Validation of a Semi-Continuous Instrument for Elemental Carbon and Organic Carbon Using a Thermal-Optical Method, Atmos. Environ. 38, 2885-2893, 2004.

Birch, M. E. and Cary, R. A.: Elemental carbon-based method for monitoring occupational exposures to particulate diesel exhaust, Aerosol Sci. Tech., 25, 221-241, 1996.

Cachier, H., Bremond, M. P., and Buat-Menard, P.: Determination of atmospheric soot carbon with a simple thermal method, Tellus, 41B, 379-390, 1989.

Cadle, S. H., Groblicki, P. J., and Stroup, D. P.: Automated carbon anaIyzer for particulate samples, Anal. Chem., 52, 2201-2206, 1980.

Cao, J. J., Lee, S. C., Zhang, X. Y., Chow, J. C., An, Z. S., Ho, K. F., Watson, J. G., Fung, K., Wang, Y. Q., and Shen, Z. X.: Characterization of airborne carbonate over a site on Asian dust source regions during spring 2002 and its climatic and environmental significance, J. Geophys. Res., 110, D03203, doi:10.1029/2004JD005244, 2005.

Cavalli, F., Viana, M., Yttri, K. E., Genberg, J., and Putaud, J.P.: Toward a standardised thermal-optical protocol for measuring 
atmospheric organic and elemental carbon: the EUSAAR protocol, Atmos. Meas. Tech., 3, 79-89, doi:10.5194/amt-3-79-2010, 2010.

Chow, J. C., Watson, J. G., Prithett, L. C., Pierson, W. R., Frazier, C. A., and Purcell, R. G.: The DRI Thermal/Optical Reflectance Carbon Analysis System: Description, Evaluation, and Applications in U.S. Air Quality Studies, Atmos. Environ., 27A, 11851201, 1993.

Chow, J. C., Watson, J. G., Crow, D., Lowenthal, D. H., Merrifield, T.: Comparison of IMPROVE and NIOSH Carbon Measurements, Aerosol Sci. Tech., 34, 23-34, 2001.

Draxler, R. R. and Rolph, G. D.: HYSPLIT (Hybrid Single-Particle Lagrangian Integrated Trajectory) Model access via NOAA ARL READY Website http://ready.arl.noaa.gov/HYSPLIT.php, NOAA Air Resources Laboratory, Silver Spring, MD, 2010.

EN12341: Air quality - determination of the $\mathrm{PM}_{10}$ fraction of suspended particulate matter. Reference method and field test procedure to demonstrate reference equivalence of measurement methods, 1998.

Escudero, M., Querol, X., Pey, J., Alastuey, A., Pérez, N., Ferreira, F., Alonso, S., Rodríguez, S., and Cuevas, E.: A methodology for the quantification of the net African dust load in air quality monitoring networks, Atmos. Environ., 41, 5516-5524, 2007.

Fuzzi, S., Andreae, M. O., Huebert, B. J., Kulmala, M., Bond, T. C., Boy, M., Doherty, S. J., Guenther, A., Kanakidou, M., Kawamura, K., Kerminen, V.-M., Lohmann, U., Russell, L. M., and Pöschl, U.: Critical assessment of the current state of scientific knowledge, terminology, and research needs concerning the role of organic aerosols in the atmosphere, climate, and global change, Atmos. Chem. Phys., 6, 2017-2038, doi:10.5194/acp-62017-2006, 2006.

Gerasopoulos, E., Kouvarakis, G., Babasakalis, P., Vrekoussis, M., Putaud, J.-P., and Mihalopoulos, N.: Origin and variability of particulate matter (PM) mass concentrations over the eastern Mediterranean, Atmos. Environ., 40, 4679-4690, 2006.

Hoornaert, S., Van Malderen, H., and Van Grieken, R.: Gypsum and other Calcium-Rich Aerosol particles above the North sea, Environ. Sci. Technol., 30, 1515-1520, 1996.

Jankowski, N., Schmidl C., Marr, I.L., Bauer, H., and Puxbaum, H.: Comparison of Methods for the Quantification of Carbonate Carbon in Atmospheric PM 10 Aerosol Samples, Atmos. Environ., 42, 8055-8064, 2008.

Kandler, K., Benker, N., Bundke, U., Cuevas, E., Ebert, M., Knippertz, P., Rodriguez, S., Schutz, L., and Weinbruch, S.: Chemical composition and complex refractive index of Saharan Mineral Dust at Izana, Tenerife (Spain) derived by electron microscopy, Atmos. Environ., 41, 8058-8074, 2007.

Koçak, M., Mihalopoulos, N., and Kubilay, N.: Contributions of natural sources to high $\mathrm{PM}_{10}$ and $\mathrm{PM}_{2.5}$ events in the eastern Mediterranean, Atmos. Environ., 41, 3806-3818, 2007.

Koulouri, E., Saarikoski, S., Theodosi, C., Markaki, Z., Gerasopoulos, E., Kouvarakis, G., Mäkelä, T., Hillamo, R., and Mihalopoulos, N.: Chemical composition and sources of fine and coarse aerosol particles in the Eastern Mediterranean, Atmos. Environ., 42, 6542-6550, 2008.

Miyazaki, Y., Kondo, Y., Han, S., Koike, M., Kodama, D., Komazaki, Y., Tanimoto, H., and Matsueda, H.: Chemical characteristics of water-soluble organic carbon in the Asian Outflow, J. Geophys. Res., 112, D22S30, doi:10.1029/2007JD009116,
2007.

NIOSH: Method 5040 (Issue 3): Elemental Carbon (Diesel Particulate), NIOSH Manual of Analytical Methods, 4rth Edition, 1999.

Phuah, C. H., Peterson, M. R., Richards, M. H., Turner, J. H., and Dillner, A. M.: A Temperature Calibration Procedure for the Sunset Laboratory Carbon Aerosol Analysis Lab Instrument, Aerosol Sci. Tech., 43, 1013-1021, 2009.

Pio, C. A., Castro, L. M., and Ramos, M. O.: Differentiated determination of organic and elemental carbon in atmospheric aerosol particles by a thermal-optical method, in: Proceedings of the Sixth European Symposium: Physico-Chemical Behaviour of Atmospheric Pollutants, edited by: Angeletti, G. and Restelli, G., Report EUR 15609/2 EN, European Commission, 706-711, 1994.

Pio, C., Alves, C., and Duarte, A.: Identification, abundance and origin of atmospheric particulate matter in a Portuguese rural area, Atmos. Environ., 35, 1365-1375, 2001.

Putaud, J.-P., Raes, F., Van Dingenen, R., Brueggemann, E., Facchini, M. C., Fuzzi, S., Gehrig, R., Hansson, H. C., Harrison, R. M., Jones, A., Laj, P., Maenhaut, W., Mihalopoulos, N., Müller, K., Palmgren, F., Querol, X., Rodriguez, S., Spindler, G., Brink, H., Tunved, P., Dingenen, R., Wehner, B., Weingartner, E., Wiedensohler, A., Wählin, P., and Raes, F.: European aerosol phenomenology - 2: chemical characteristics of particulate matter at kerbside, urban, rural and background sites in Europe, Atmos. Environ., 38, 2579-2595, 2004.

Putaud, J.-P., Van Dingenen, R., Alastuey, A., Bauer, H., Birmili, W., Cyrys, J., Flentje, H., Fuzzi, S., Gehrig, R., Hansson, H. C., Harrison, R. M., Herrmann, H., Hitzenberger, R., Huglin, C., Jones, A. M., Kasper-Giebl, A., Kiss, G., Kousa, A., Kuhlbusch, T. A. J., Loschau, G., Maenhaut, W., Molnar, A., Moreno, T., Pekkanen, J., Perrino, C., Pitz, M., Puxbaum, H., Querol, X., Rodriguez, S., Salma, I., Schwarz, J., Smolik, J., Schneider, J., Spindler, G., ten Brink, H., Tursic, J., Viana, M., Wiedensohler, A., Raes, F.: A European aerosol phenomenology - 3: Physical and chemical characteristics of particulate matter from 60 rural, urban, and kerbside sites across Europe, Atmos. Environ., 44, 1308-1320, 2010.

Querol, X., Alastuey, A., Ruiz, C. R., Artiñano, B., Hansson, H. C., Harrison, R. M., Buringh, E., ten Brink, H. M., Lutz, M., Bruckmann, P., Straehl, P., and Schneider, J.: Speciation and origin of $\mathrm{PM}_{10}$ and $\mathrm{PM}_{2.5}$ in selected European cities, Atmos. Environ., 38, 6547-6555, 2004.

Querol, X., Pey, J., Pandolfi, M., Alastuey, A., Cusack, M., Pérez, N., Moreno, T., Viana, M., Mihalopoulos, N., Kallos, G., and Kleanthous, S.: African dust contributions to mean ambient $\mathrm{PM}_{10}$ mass-levels across the Mediterranean Basin, Atmos. Environ., 43, 4266-4277, 2009.

Schauer, J. J., Mader, B. T., DeMinter, J. T., Heidemann, G., Bae, M. S., Seinfeld, J. H., Flagan, R. C., Cary, R. A., Smith, D., Huebert, B. J., Bertram, T., Howell, S., Quinn, P., Bates, T., Turpin, B., Limp, H. J., Yu, J., Yang, C. H., and Keywood, M. D.: ACEAsia intercomparison of a thermal-optical method for the determination of particle-phase organic and elemental carbon, Environ. Sci. Tech., 37, 993-1001, 2003.

Schmid, H., Laskus, L., Abraham, H. J., Baltensperger, U., Lavanchy, V., Bizjak, M., Burba, P., Cachier, H., Crow, D., Chow, J., Gnauk, T., Even, A., Ten Brink, H. M., Giesen, K.-P., Hitzenberger, R., Hueglin, C., Maenhaut, W., Pio, C., Carvalho, A., 
Putaud, J.-P., Toom-Sauntry, D., and Puxbaum, H.: Results of the "carbon conference" international aerosol carbon round robin test stage I, Atmos. Environ., 35, 2111-2121, 2001.

Sciare, J., Cachier, H., Oikonomou, K., Ausset, P., SardaEstève, R., and Mihalopoulos, N.: Characterization of carbonaceous aerosols during the MINOS campaign in Crete, JulyAugust 2001: a multi-analytical approach, Atmos. Chem. Phys., 3, 1743-1757, doi:10.5194/acp-3-1743-2003, 2003.

Sillanpää, M., Frey, A., Hillamo, R., Pennanen, A. S., and Salonen, R. O.: Organic, elemental and inorganic carbon in particulate matter of six urban environments in Europe, Atmos. Chem. Phys., 5, 2869-2879, 2005, http://www.atmos-chem-phys.net/5/2869/2005/.

Subramanian, R., Khlystov, A. Y., and Robinson, A. L.: Effect of Peak Inert-Mode Temperature on Elemental Carbon Measured Using Thermal-Optical Analysis, Aerosol Sci. Tech., 40, 763$780,2006$.
Xu, J., Bergin, M. H., Greenwald, R., Schauer, J. J., Shafer, M. M., Jaffrezo, J. L., and Aymoz, G.: Aerosol chemical, physical, and radiative characteristics near a desert source region of northwest China during ACE-Asia, J. Geophys. Res., 109, D19S03, doi:10.1029/2003JD004239, 2004.

Yttri, K. E., Aas, W., Bjerke, A., Cape, J. N., Cavalli, F., Ceburnis, D., Dye, C., Emblico, L., Facchini, M. C., Forster, C., Hanssen, J. E., Hansson, H. C., Jennings, S. G., Maenhaut, W., Putaud, J. P., and Tørseth, K.: Elemental and organic carbon in $\mathrm{PM}_{10}$ : a one year measurement campaign within the European Monitoring and Evaluation Programme EMEP, Atmos. Chem. Phys., 7, 5711-5725, doi:10.5194/acp-7-5711-2007, 2007.

Yu, J. Z., Xu, J., and Yang, H.: Charring Characteristics of Atmospheric Organic Particulate Matter in Thermal Analysis, Environ. Sci. Tech., 36, 754-761, 2002. 